D.O.I.: $10.3895 / \mathrm{S} 1808-04482010000100003$

\title{
IMPACTOS DE POLÍTICAS DE SUPRIMENTO NO DESEMPENHO DE EMPRESAS DE MÉDIO PORTE DO SETOR MOVELEIRO SOB A ÓTICA DA NETWORK THEORY
}

\section{IMPACTS OF SUPPLY POLICIES IN THE MEDIUM-SIZED ENTERPRISES PERFORMANCE OF FURNITURE INDUSTRIAL CLUSTER BASED ON NETWORKING THEORY APPROACH}

\author{
Wescley Silva Xavier ${ }^{1}$; Osmar Vieira de Souza Filho ${ }^{2}$; Ricardo Silveira Martins ${ }^{3}$ \\ ${ }^{1}$ Centro de Pós-Graduação e Pesquisas em Administração da Universidade Federal de Minas Gerais \\ - CEPEAD/UFMG - Belo Horizonte - Brasil \\ wescleysxavier@yahoo.com.br \\ ${ }^{2}$ Centro de Pós-Graduação e Pesquisas em Administração da Universidade Federal de Minas Gerais \\ - CEPEAD/UFMG - Belo Horizonte - Brasil \\ osmar.br@gmail.com \\ ${ }^{3}$ Centro de Pós-Graduação e Pesquisas em Administração da Universidade Federal de Minas Gerais \\ - CEPEAD/UFMG - Belo Horizonte - Brasil \\ ricardomartins.ufmg@gmail.com
}

\begin{abstract}
Resumo
Esse estudo analisou as estratégias de suprimento de duas empresas de médio porte do setor moveleiro, especialmente no que se refere à gestão do relacionamento com fornecedores. A pesquisa caracteriza-se por ser um estudo multi-casos de abordagem qualitativa-descritiva, sendo utilizadas entrevistas semi-estruturadas submetidas à Análise de Conteúdo (AC). O modelo teórico da análise foi apoiado na Network Theory a partir de seus pilares básicos (atores, atividades e recursos), para a análise das estratégias utilizadas pela função compras nas empresas, para: coordenar a execução das atividades desempenhadas pelos fornecedores; combinar recursos internos com recursos externos; gerenciar projetos colaborativos entre a empresa e fornecedores; interagir com a estrutura de fornecedores. $O$ estudo identificou que as distintas estratégias de suprimento utilizadas pelas duas empresas produzem diferentes impactos em seus desempenhos: a primeira é afetada de maneira negativa, particularmente por preterir politicas de relacionamento em detrimento de uma manutenção de poder frente aos fornecedores. Já a segunda empresa, é afetada de maneira positiva, obtendo ganhos significativos a partir de políticas de relacionamento colaborativo junto aos seus fornecedores.
\end{abstract}

Palavras-chave: cadeia de suprimentos; networking theory; desempenho logístico; setor moveleiro.

\section{Introdução}

O desenvolvimento de relacionamentos cooperativos entre parceiros de negócios é uma fonte importante de obtenção de vantagens competitivas, de acordo com a abordagem da Network 
Theory. Tal abordagem assume que as relações cooperativas tendem a ser estáveis e a possuir foco no longo prazo.

A posição de uma empresa em uma cadeia de suprimentos é baseada em seu conjunto total de relacionamentos, e cada empresa se diferencia das outras pela sua estrutura, pelos seus produtos, pelos elementos constitutivos desses produtos - ou seja, seus insumos -, pelas especificidades de seus fornecedores, pelos problemas que elas precisam resolver para auxiliar os seus clientes e pelos relacionamentos dos quais elas dependem.

Portanto, pelos fatores apontados, conclui-se que uma das formas mais prováveis de que tal empresa consiga desenvolver a sua posição na cadeia de suprimentos é através da interação com o grupo de diferentes empresas que compõe o seu conjunto de relacionamentos. Tais interações afetam diretamente a forma de acesso aos recursos externos necessários para sua operação.

Os relacionamentos em uma rede de empresas estão interconectados entre si. O comportamento de uma empresa em um relacionamento com um cliente importante, por exemplo, será influenciado pelo relacionamento que ela mantém com seu conjunto de fornecedores. Tais conexões, consequentemente, afetam o desempenho de uma empresa.

As atividades internas desempenhadas por uma empresa - sejam elas de natureza logística, operacional, mercadológica ou administrativa - se interligam às atividades desempenhadas por fornecedores e clientes. A eficiência e agilidade nas operações de recebimento de mercadorias de uma empresa dependerá das características da carga a ser recebida e da maneira como tal carga foi embalada, unitizada, transportada e entregue pelo fornecedor. Portanto, atividades logísticas desempenhadas pelo fornecedor afetarão as atividades logísticas do cliente.

Assim, pode-se afirmar que a forma como as empresas gerenciam a interligação entre suas atividades internas será um fator de produtividade das empresas envolvidas e da rede de suprimentos como um todo.

Este estudo busca avaliar o impacto das políticas de suprimentos de empresas de médio porte, especialmente no que se refere ao estabelecimento de vínculos com fornecedores estratégicos, sobre o desempenho operacional destas empresas. Utilizou-se como fundamentação teórica as proposições da Network Theory, especialmente em suas três camadas de análise: estrutura de atividades, de recursos e de atores.

\section{A Abordagem da network theory}

Uma das características das cadeias de suprimento é a formação de parcerias como estratégia de concorrência, que se consolida com a utilização de recursos complementares de terceiros e o compartilhamento das responsabilidades via distribuição de atividades (MONCZKA et al, 2002). O 
desenvolvimento de relacionamentos cooperativos entre parceiros de negócios é, de acordo com a corrente de pesquisadores que defendem esta abordagem, uma fonte importante de obtenção de vantagens competitivas, assumindo que as relações cooperativas tendem a ser estáveis e a possuir foco no longo prazo (HAKANSSON; SNEHOTA, 1995; SKJOETT-LARSEN, 1999; GADDE; HAKANSSON, 2001; FORD et al, 2001; BRITO; ROSEIRA, 2003).

Skjoett-Larsen (1999) aponta como enunciado fundamental para a Network Theory o fato de que empresas individuais necessitam de recursos controlados por outras empresas e que a interação entre elas é a forma de acesso a esses recursos externos. O modelo de network aponta as "atividades", os "recursos" e os "atores" como três aspectos interdependentes de uma rede (SKJOETT-LARSEN, 1999; OLSEN, 2006).

Atores são definidos como aqueles membros de uma rede de relacionamentos que, de forma isolada ou conjunta, controlam recursos e desempenham atividades (BRITO; ROSEIRA, 2003; OLSEN, 2006). Possuem intenções e metas, e esforçam-se por aumentar o seu controle, mas não agem de forma isolada.

A abordagem da Network Theory afirma que os negócios não são conduzidos necessariamente por um fornecedor ativo e um cliente passivo. Cada ação de compra e venda faz parte de um contexto maior, chamado de "relacionamento", em que o conjunto de ações executadas influencia a forma como um evento único será desempenhado, assim como as demais ações de compra e venda simultâneas com outros atores também influenciam a forma como um simples evento é conduzido.

As empresas têm pouca autonomia para agir de forma independente e suas ações são influenciadas pelas atitudes e ações dos demais atores com os quais elas se relacionam. Portanto, o desenvolvimento de estratégias de negócios não deve levar em consideração apenas aspectos internos das empresas; faz-se necessário analisar o conjunto total de relacionamentos mantidos pelas mesmas. Hakansson e Snehota (1995) afirmam que, muitas vezes, os fatores que interferem nos relacionamentos entre duas empresas em uma rede são externos a elas.

Dessa forma, as empresas devem ser vistas como membros de redes de negócios que consistem, por sua vez, de um grande número de empresas heterogêneas que se interagem em busca de soluções para seus diferentes problemas. Tais interações afetam diversas outras empresas da rede de suprimentos (FORD et al, 2003).

Além do atributo de interdependência, Gadde e Hakansson (2001) apóiam a tese de que há conexões específicas entre os relacionamentos estabelecidos por uma empresa. Tais conexões específicas podem ocorrer nas mais diversas situações: o relacionamento entre uma empresa e seu principal cliente, por exemplo, pode ter uma conexão com o relacionamento com outros clientes, fornecedores, bancos ou empresas de consultoria. 
Um número limitado de relacionamentos tem, por regra, um significativo efeito no desempenho das empresas (HAKANSSON; SNEHOTA, 1995). Mas, ao mesmo tempo, o desempenho de uma empresa em todo o seu conjunto de relacionamentos afeta o seu desempenho em um relacionamento específico. Então, existe uma ligação direta entre relacionamentos e desempenho. Portanto, uma empresa que deseje aprimorar a performance deve empenhar-se em estabelecer conexões entre todos os seus relacionamentos.

Mas qual é o conceito de relacionamento? Segundo Hakansson e Snehota (1995), relacionamento é o resultado de um processo de interação, em que conexões entre dois parceiros são desenvolvidas para produzir uma orientação mútua e comprometimento. Produzem algo que nenhum dos dois parceiros envolvidos obteria atuando de forma isolada e um status que não pode ser facilmente duplicado.

Dois relacionamentos não são iguais entre si, apesar de haver algumas similaridades entre eles. Ainda, há um certo padrão no efeito que eles produzem, capturado por meio de três camadas: estrutura de atividades; estrutura de recursos; e estrutura de atores.

\subsection{Estrutura de atividades}

As empresas desempenham diversas atividades internamente, com o objetivo de desenvolver produtos ou serviços, adquirir os materiais ou serviços necessários e produzir, comercializar e entregar tais produtos ou serviços. Porter (1991) definiu o conjunto de atividades como sendo a cadeia de valor da empresa.

De acordo com a perspectiva da Network Theory, a preocupação predominante reside na compreensão da maneira como as atividades desempenhadas por uma empresa afetam as atividades desempenhadas pelas outras empresas e no modo como a empresa, por sua vez, é afetada pelas atividades desempenhadas externamente (GADDE; HAKANSSON, 2001). Portanto, o desempenho de uma empresa é afetado pela forma como suas atividades internas se conectam com as atividades de um parceiro (HAKANSSON; SNEHOTA, 1995).

Atividades são executadas em uma seqüencia - ou uma cadeia de atividades, sendo vinculadas diretamente a uma saída específica (GADDE; HAKANSSON, 2001). Quanto mais firme for a ligação entre essas atividades, mais forte será a interdependência elas (HAKANSSON; SNEHOTA, 1995; GADDE; HAKANSSON, 2001).

Tais ligações representam, assim, uma forma de coordenação, atingida por meio de adaptações, ou seja, ajustes mútuos efetuados nas atividades, produtos, sistemas administrativos e processos de produção (SKJOETT-LARSEN, 1999). Tais ajustes se referem ao fato de atividades poderem ser desempenhadas de forma padronizada para diversas situações e de uma forma única 
em outras situações, a depender da contraparte a que estiver associada. Essas adaptações são o ingrediente crítico para os relacionamentos interorganizacionais.

Para exemplificar tal concepção teórica, pode-se citar o caso de uma empresa fabricante de calçados masculinos, cujos modelos produzidos seguem um padrão único. Porém, ao atender a um cliente detentor de uma marca reconhecida pelos consumidores, tal fabricante pode adaptar algumas atividades produtivas, a fim de oferecer os mesmos modelos com pequenas modificações de estilo e matéria-prima, além de ser finalizado com a marca do cliente estampada no produto, ao invés da sua marca própria.

Adaptações existentes em decorrência de um relacionamento podem ser realizadas por uma ou por ambas as empresas envolvidas, mas as duas sempre serão afetadas. Emergem ao longo do tempo, como uma maneira de se resolver problemas (HAKANSSON; SNEHOTA, 1995), um meio para aprimorar a performance, apesar de significar algum custo (GADDE; HAKANSSON, 2001), e uma forma de melhor explorar os recursos no âmbito da network (SKJOETT-LARSEN, 1999).

Portanto, a eficiência em uma cadeia de atividades está relacionada à firmeza das ligações estabelecidas entre elas. Como exemplo, Gadde e Hakansson (2001) utilizam a indústria de computadores pessoais. Empresas que utilizam a estratégia de canal direto - como é o caso da Dell - personalizam com mais frequência os seus produtos de acordo com o desejo do cliente, exigindo perfis de atividades internas diferentes daqueles exigidos pelas empresas que utilizam uma estratégia de canal tradicional, cujos produtos apresentam graus maiores de padronização.

\subsection{Estrutura de recursos}

A segunda camada é formada pelos recursos necessários e pelos recursos controlados pelas empresas, os quais sustentam as atividades desempenhadas. Eles são uma combinação de recursos tangíveis - como pessoal, equipamentos, prédios, capital - e intangíveis - como conhecimento, imagem e marca.

Nenhuma empresa isoladamente possui todos os recursos de que precisa para operar. Portanto, será necessário interagir com outras empresas para obter acesso aos recursos necessários. As empresas fornecem recursos umas para as outras, e por esse motivo eles são um importante fator a influenciar os relacionamentos de negócios (HAKANSSON; SNEHOTA, 1995).

A visão da Network Theory considera os recursos como conceitos relativos, implicando que o valor de um recurso específico não é estático, mas está relacionado com a sua utilidade, ou seja, com o tipo de recurso com o qual ele será combinado (OLSEN, 2006).

Obter acesso aos vários tipos de recursos - tangíveis e intangíveis - é um importante motivador para o estabelecimento de relacionamentos de negócios. Tais recursos serão integrados, 
transformando o relacionamento em um conjunto desses recursos interligados. Além disso, novas combinações de recursos possivelmente emergirão à medida que o relacionamento se desenvolva. Devido a essa característica, um relacionamento pode também ser considerado, ele próprio, como um recurso - talvez o mais significativo recurso dentre todos. Deve ser utilizado de uma maneira eficiente, garantindo o acesso a recursos de outros que afetam o desempenho de uma empresa individual. Relacionamentos não perdem seu valor à medida que são utilizados, sendo que freqüentemente se valorizam com o passar do tempo.

A forma de combinação entre os recursos que são mobilizados a partir de relacionamentos e os recursos internos reflete o conhecimento e as habilidades de uma empresa no seu uso e na produção desses recursos. À medida que essas combinações se desenvolvem, o conhecimento de como fornecer e de como utilizar os diferentes recursos e suas características se desenvolve. Portanto, a interação com outras empresas leva a um aprendizado sobre a melhor forma de produzir e utilizar a combinação entre os recursos.

\subsection{Estrutura de atores}

Por fim, a terceira camada é formada pelos atores envolvidos na network, os quais estabelecem vínculos que afetarão a forma como percebem, avaliam e tratam um relacionamento entre si, com terceiros e com cada situação vivenciada em suas operações. Os autores da Network Theory consideram as empresas como atores que agem baseados na identidade construída a partir da interação estabelecida com outras empresas.

Duas empresas podem estabelecer entre si um relacionamento próximo, caracterizado pela cooperação, enquanto tentativas de estabelecer o mesmo tipo de relacionamento com outras empresas podem falhar, a despeito de possuírem estruturas de recursos e de atividades similares. A explicação para tal situação está no fato de que as empresas se relacionam de acordo com a percepção que os atores envolvidos possuem sobre si próprios e sobre os demais.

Tais vínculos estabelecidos entre atores - classificados por Hakansson e Johanson como técnicos, sociais, administrativos e legais (apud SKJOETT-LARSEN, 1999) - desenvolvem-se à medida que as empresas adquirem confiança e comprometimento, fruto do progresso do relacionamento entre elas.

Como conseqüência do aprimoramento desses vínculos, tornam-se mais comprometidas entre si, priorizando uma à outra, em um processo de construção de uma identidade que reflita essa característica. A identidade assumida e criada, portanto, reflete o grau de conexão estabelecido entre duas empresas, sendo capaz de fortalecer ou limitar o relacionamento. O desenvolvimento da confiança é um processo social típico para o desenvolvimento do relacionamento. Tal processo é 
dependente não somente da interação direta entre as partes, mas da percepção sobre o relacionamento da contraparte com terceiros.

Portanto, o comportamento de cada um dos atores no processo de interação depende da identidade por eles assumida em seus outros relacionamentos. Cada ator irá, em alguma extensão, representar também sua contraparte em seus relacionamentos com terceiros. Tais terceiros perceberão o relacionamento entre esses dois parceiros como um fato e buscarão adaptar-se, dando ao conjunto de relacionamentos uma identidade coletiva, distinta por sua natureza. Conseqüentemente, à medida que vínculos são estabelecidos, surge uma estrutura organizada de atores - uma network.

Vínculos são, portanto, pré-requisitos para o efetivo aprendizado mútuo, para o desenvolvimento das capacidades dos atores envolvidos e para a mobilização de recursos externos a elas - uma necessidade, por exemplo, em um contexto de mudança (HAKANSSON; SNEHOTA, 1995).

Para esses autores, há relacionamentos entre empresas que se consistem principalmente em um vínculo entre os atores. Outros possuem também integração entre os recursos, mas sem muita ligação entre as atividades. Outros ainda podem possuir forte ligação entre as atividades enquanto tanto o vínculo entre os atores quanto a integração entre os recursos são fracos.

O relacionamento entre duas empresas pode ser caracterizado pela importância relativa de cada uma destas camadas. Quanto mais efeitos a configuração dessas três camadas provocar em um relacionamento, mais complexo ele será. A substância do relacionamento entre duas empresas não será uma mera soma do que as partes oferecem à outra; será algo qualitativamente diferente, influenciado pelas ligações, combinações e vínculos.

Em resumo, o relacionamento entre duas empresas terá um perfil que expressa o nível das ligações estabelecidas entre as atividades desempenhadas, da combinação entre a estrutura de recursos disponíveis e dos vínculos estabelecidos entre os atores. O status momentâneo dessa configuração pode ser utilizado para caracterizar a natureza de um relacionamento desenvolvido entre duas empresas. A interação entre essas três dimensões - vínculos entre atores, combinação entre recursos e ligações entre atividades - representa a força que guia o desenvolvimento dos relacionamentos de negócios. $\mathrm{O}$ valor da rede de relacionamentos resultante da interação entre os atores em uma network dependerá de como cada uma dessas camadas será gerenciada pelas empresas (HAKANSSON; SNEHOTA, 1995; SKJOETT-LARSEN, 1999). 


\section{Metodologia}

O presente trabalho tem por objetivo avaliar o impacto das políticas de suprimentos de empresas de médio porte, especialmente no que se refere ao estabelecimento de vínculos com fornecedores estratégicos, sobre o desempenho operacional destas empresas. A condução da pesquisa se deu por meio de estudos multi-casos de natureza qualitativa com fins descritivos, dado o caráter de intersubjetividade presente na pesquisa (YIN, 2002).

A unidade de análise é composta por duas empresas de médio porte do Arranjo Produtivo Local (APL) Moveleiro de Ubá-MG, terceiro mais importante do Brasil, sendo o critério de seleção a acessibilidade e a conveniência. Já as unidades de observação estão compostas por atores organizacionais da área de logística, em níveis de propriedade, diretoria, gerência e operacional, a fim de que as verbalizações sobre um determinado tema possam ser confrontadas, sendo a seleção das unidades por acessibilidade e julgamento. Quanto à coleta de dados, foram utilizadas entrevistas semi-estruturadas para posterior análise, com uma estrutura de eixos temáticos pré-definidos, mas abertas a novas inserções que possam surgir no trabalho de campo (SEIDMAN, 1991).

Em relação aos eixos temáticos destinados a compreender a formação das estratégias de compras foram definidas as seguintes categorias: histórico do gerenciamento de atividades de compras; alocação das compras dentro da organização; intersecção entre estratégia e atividades de compras; práticas de compras atuais; política de relacionamento com parceiros e; utilização de sistemas de informação.

Para análise das entrevistas foi utilizada a técnica da Análise de Conteúdo (AC). Esta técnica visa denotar de maneira plausível elementos ocultos da linguagem humana, além de organizar e possibilitar a descoberta de significados originais dos seus elementos manifestos (BARDIN, 1977; TRIVIÑOS, 1987). O que se pretendeu com a utilização da AC é identificar variáveis, restrições, motivações, atitudes, crenças e tendências explícitas e implícitas que circundam aspectos de estratégia na área de logística. Além, como ressalta Triviños (1987), a AC possibilita também desvelar aspectos ideológicos que podem existir em dispositivos como diretrizes e princípios, os quais se acredita aqui poderem ser encontrados no que é subjacente ao pensamento acerca das estratégias das empresas.

Observou-se aqui a inter-relação entre as atividades da função compras e as atividades das demais funções, uma vez que é pressuposto a necessidade de alinhamento intra-organizacional entre as funções logísticas. Ademais, os resultados foram analisados sob a ótica da network theory, sendo pano de fundo para esta análise os pilares básicos da teoria (atores, atividades e recursos), no que diz respeito a coordenar a execução das atividades desempenhadas pelos fornecedores, combinar 
recursos internos com recursos externos, gerenciar projetos colaborativos entre a empresa e fornecedores, e interagir com a estrutura de fornecedores

\section{Apresentação dos casos}

\subsection{A política de suprimentos na empresa alfa}

A empresa Alfa comercializa cozinhas de aço desde a sua fundação e há quatro anos iniciou a produção de cozinhas e dormitórios de madeira. Esta inclusão se deve à grande dependência da produção de móveis de aço, no que diz respeito à variação do preço do minério de ferro, conseqüentemente, do aço. Para ilustrar, o entrevistado "E4" ressalta que no início de 2008 este aumento foi de $70 \%$ para o minério de ferro e $40 \%$ de aço, que permite analisar esse aumento de mix com móveis de madeira, como uma forma de reduzir o risco, a partir da diversificação da oferta.

A preocupação com a dependência do preço do aço parece ser relevante, uma vez que esta matéria corresponde a $40 \%$ do custo de produção da empresa. Particularmente, porque a relação de compra é estabelecida em um setor monopolístico, no qual existem apenas dois fornecedores, CSN (Companhia Siderúrgica Nacional) e Usiminas, reduzindo por completo qualquer tentativa de negociação por parte da empresa Alfa. Uma saída para reduzir essa relação de total dependência seria a importação do aço, mas ao optar por esta estratégia, a empresa Alfa torna-se suscetível a retaliações por parte dos fornecedores.

\footnotetext{
"Chapa (de aço) não tem muito como você negociar (...) se você quer, quer, se não quer, (o fornecedor) exporta. Então, a gente tem que aceitar o que vem. A gente tentou até importar alguma coisa aí. Chegamos a importar nesse ano umas mil toneladas da Turquia. Mas quando você começa a importar, você tem uma pressão dos fornecedores internos. A gente compra por cota, e se você começa a importar muito a sua cota de compras cai. Eles fazem uma média. 'Nos três primeiros meses você comprou uma média de 2500 toneladas'. Então, se você começa a importar, você começa baixar sua média de compras com eles. Depois, se você tiver um preço mais alto no mercado externo e quiser comprar deles, eles não te vendem. Então, é muito arriscado até para a cotação do produto. Porque eles trabalham com média. Aí, você vai ter que comprar mais caro porque você não comprou deles" (E2).
}

A empresa Alfa adota uma estratégia de não trabalhar com apenas um fornecedor por item. De acordo com E1, “é norma aqui de ter no mínimo dois fornecedores para cada material”. O número de fornecedores depende das características da matéria-prima, podendo variar de dois a cinco fornecedores.

Para ilustrar, destaca-se que a madeira, representativa pelo seu volume, é comprada de quatro ou cinco fornecedores, justificado por E4 devido à baixa qualificação disponível no mercado. Por outro lado, a opção por um número de dois ou mais fornecedores também é justificada pelo 
risco de faltar matéria-prima, e o número de empresas fornecedoras aumenta conforme a capacidade de entrega destas, como relatado no trecho abaixo:

\footnotetext{
"Por exemplo, a gente tem hoje cinco fornecedores de vidro. Eu não consigo no mercado um fornecedor apenas, que nos consiga suprir todo consumo. Então, eu preciso dividir. Qualquer fornecedor que eu coloque sozinho, um ou dois, provavelmente nós vamos ter problema de fornecimento, porque o volume é grande" (E1).
}

Embora seja válido considerar iminente a existência do risco de se trabalhar com apenas um fornecedor, parece plausível analisar este risco sob dois aspectos: a experiência desfavorável na compra do aço e a possível preferência por um maior número de pequenos fornecedores. O primeiro aspecto poderia reforçar a percepção do risco de trabalhar com um baixo número de fornecedores devido à relação de dependência que se estabeleceria, particularmente, frente a grandes fornecedores, como é o caso do aço.

O segundo aspecto seria, de certa maneira, decorrente do primeiro, uma vez que a alternativa à não dependência de grandes fornecedores seria a predileção por um número maior de pequenos fornecedores, que não apenas reduz o risco por haver um número maior de alternativas, mas também desloca o peso da relação comercial em favor da empresa Alfa, dado o seu poder de compra ser, quase sempre maior, que o de atendimento dos fornecedores.

Outro aspecto que reforça esta perspectiva é o formato de escolha dos fornecedores. De acordo com o entrevistado E2, a empresa Alfa "está sempre fazendo teste, avaliando fornecedor e tudo". Porém, o que define comprar de um fornecedor e não de outro seria:

\footnotetext{
"Preço e qualidade, entrega também, mas preço... A gente é sempre aberto a novos fornecedores, até para ver preço e qualidade. Vem, faz o teste e se funcionou bem a gente fica no máximo com três. Mas a maioria são dois. Aí, um sai, sempre que tiver com preço maior para dar lugar para outro, para a gente não abrir muito a gama de fornecedores nosso" (E2).
}

A fala do entrevistado traz elementos explícitos que indicam que, apesar de considerar aspectos como qualidade e capacidade de entrega na escolha dos fornecedores, o que é determinante para a seleção de fornecedores é o preço oferecido por cada um. É esta possibilidade de substituir um fornecedor em função de um melhor preço que suscita a análise do principal elemento implícito na fala do entrevistado, no caso, a falta de estratégias de compra que visem a formação de parcerias duradouras com fornecedores.

Quanto ao envio de materiais com avarias, embora a gerência de estoques declare realizar o controle de qualidade por amostragem das compras, uma barreira para a uniformidade dos materiais recebidos é o fato de se trabalhar com fornecedores variados. 
“(...) a gente faz (controle) por amostragem, não tem como inspecionar, abrir vários pacotes ali de acordo com o que vai descarregando, você faz aleatório, tira um e faz uma média e confere. (...) Tem alguns itens que são problemáticos para o controle de qualidade. $O$ vidro, por exemplo. Nós trabalhamos com um vidro que é comum a vários fornecedores. Quando dá um problema de qualidade, para você saber qual vidro que deu problema é muito complicado. Não tem uma marca no vidro, não tem nada, só aquele vidro 300 por 450 . Nós trabalhamos com oito fornecedores" (E6).

A existência de elementos explícitos na fala do entrevistado aponta para a dificuldade de uniformizar a qualidade da matéria-prima devido à variedade de fornecedores. Embora haja um argumento que relate a qualidade como um atributo pelo qual a empresa prima, essa perspectiva se desfaz, quando a empresa opta por trabalhar com um número elevado de fornecedores.

Ademais, verifica-se também a reincidência da falta de uma política que prime pelo relacionamento duradouro com determinados fornecedores, que poderia representar um trade-off a fim de equilibrar o risco percebido pela empresa ao trabalhar com um baixo número de fornecedores e a aparente perda de poder de negociação, com a uniformidade da qualidade da matéria-prima e os benefícios adquiridos no relacionamento estabelecido.

Não há compartilhamento de informações entre as partes - Alfa e seus fornecedores. Em decorrência, o que se verifica é a imprevisibilidade na chegada das matérias primas, levando a empresa a adotar um nível de estoque de segurança elevado para que não haja ruptura de estoque.

“(...) só recebo a programação do que vai ser produzido. O que acontece, o que vai ser produzido, eu já tenho em mãos, mas o que vai chegar de material, não._...) Se todos os fornecedores comunicassem o dia que estariam chegando a mercadoria... Se eu tivesse uma relação do que vai chegar durante a semana, eu conseguiria controlar muito melhor." (E6).

As atividades do setor de compras são orientadas pela programação gerada no PCP (Planejamento e Controle da Produção). Após a entrada dos pedidos via departamento comercial, os pedidos são processados e é gerada a lista de materiais necessários para atender a produção. Em relação aos móveis de aço, a empresa trabalha com pedidos para um horizonte de 15 dias. Já para os móveis de madeira, são alocados pedidos para até 60 dias futuros.

\footnotetext{
"A base é o orçamento, o orçamento de vendas. Dentro desse volume total de orçamento, eles vão dissecando cada produto ou cada linha de produto, até chegar ao nível que eles estão prevendo que vai vender. Aí, é experiência de mercado de cada um. Normalmente, eles sabem que vai entrar um pedido grande de tal cliente. Nesse mês, tal cliente já comprou muito e não vai comprar mais esse mês, ou provavelmente, só vai comprar no final do mês que vem. Aí, é uma questão comercial, quem faz essa previsão de vendas é comercial. E considera também a carteira de pedido já feita” (E1).
}

Os elementos em destaque, na fala do entrevistado, remetem à informalidade e experiência adquirida para a previsão de vendas e também de compras. Embora esta formação cognitiva represente, de certa forma, uma curva de aprendizagem por parte dos responsáveis pelas previsões, 
há que se considerar os riscos de uma previsão equivocada. Além disso, pode ser um mecanismo que mascare ou substitua um alinhamento junto aos parceiros próximos aos clientes finais, que poderiam subsidiar as previsões com base em informações mais confiáveis.

A empresa Alfa adota uma estratégia de contratação de fornecedores de serviços de transporte para $60 \%$ da sua produção. Os demais $40 \%$ são transportados por frota própria perfazendo um total de 48 caminhões próprios e 74 agregados.

A opção pelo serviço de terceiros se dá pela contratação de agregados - proprietários de um ou dois caminhões residentes na cidade de Ubá-MG. Tal escolha se dá sob uma tríade de elementos já encontrados em outras funções logísticas, particularmente a redução de custo, a manutenção do poder de negociação e a falta de políticas de relacionamentos duradouros. Já a manutenção de uma parcela de transporte próprio não é permeada pela redução de custos, mas sim, pelos outros dois elementos - manutenção do poder de negociação e a falta de políticas de relacionamentos duradouros.

Diversos fatores fortalecem a ilação supracitada. O primeiro deles seria o fato de a empresa Alfa utilizar terceiros apenas para destinos mais distantes. Essa designação ocorre porque a empresa Alfa não precisa arcar com o frete de retorno - que gera receita, dilui os custos fixos e cobre os custos variáveis - uma vez que caberia ao prestador de serviços a busca de alternativas para este frete.

\footnotetext{
"Nós trabalhamos com os terceiros, porque nós pagamos só o frete de ida. O frete de volta é o que cobre o custo deles. Nós pagamos o frete de ida, eles vão até determinadas regiões e eles trazem o frete de retorno por conta deles (...)." (E4).

"O custo do transporte de terceiros é muito mais interessante. Hoje, para você ter uma idéia, o nosso custo por quilômetro dá $\mathrm{R} \$ 1,80$, da nossa frota. Aí meu carro vai e volta. Tem que pagar ele até o destino final, que é aqui. Já o terceiro, eu pago a ele R\$ 1,90 e ele vai para Salvador. Eu pago a ele até lá, de lá acabou meu compromisso com ele, eu só pago ida. Então, enquanto o meu eu pago a ida e a volta, eu pago a ele só a ida, e de lá ele pega retorno por conta própria. E não tem investimento de frota. Nós só temos a (frota) estratégica para não ficarmos $100 \%$ na mão deles (terceiros)" (E3).
}

Neste último argumento, percebe-se uma argumentação que exime a empresa Alfa de qualquer tipo de comprometimento com o prestador de serviço, de forma que as atribuições de cada um na transação estejam demarcadas, caracterizando então, a inexistência de políticas de relacionamento.

Ademais, a verbalização apresenta um argumento que traz outra carga implícita para a manutenção do poder nas negociações, ao passo em que ter frota própria significa uma alternativa a transações que fujam ao que é definido pela empresa Alfa. Por fim, a opção por pequenos transportadores em função do custo e a falta de comprometimento, pode ser analisada a partir de 
elementos silenciados, no caso, se este tipo de parceria seria aceito por uma transportadora que, legitimamente, apresenta maior poder de negociação.

Os elementos da figura dois, a seguir, representam a inter-relação, entre as funções logísticas, como as decisões e políticas mais significativas, a influência de variáveis exógenas e os efeitos na logística da empresa.

Figura 1- Síntese da formação de estratégias logísticas na empresa Alfa

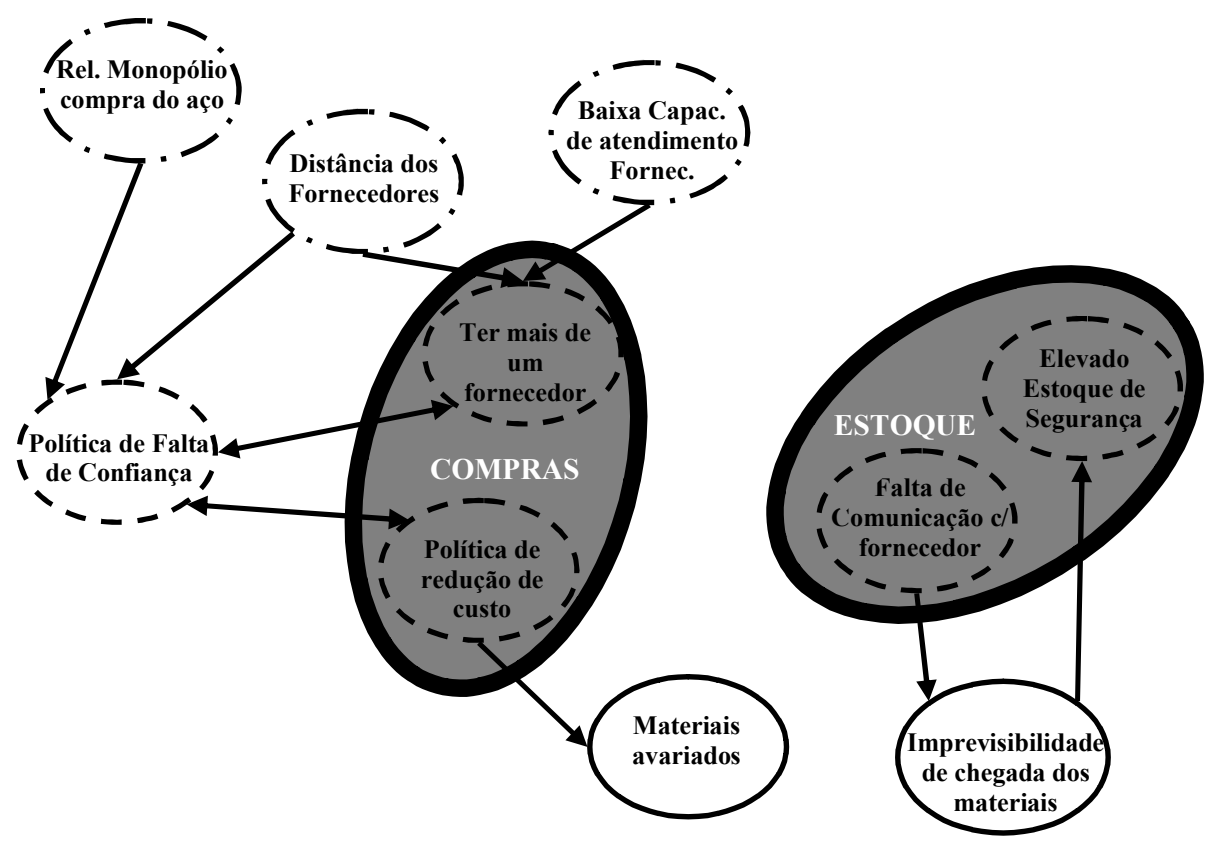

LEGENDA

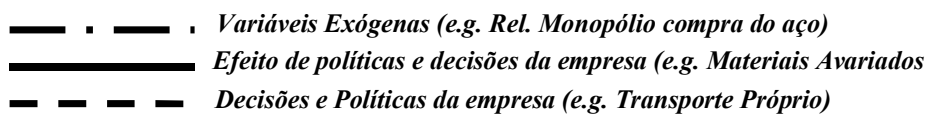

Fonte: Dados da pesquisa.

\subsection{A política de suprimentos na empresa beta}

A empresa Beta comercializa móveis de madeira, especificamente salas de jantar, home e peças decorativas, e sua estrutura se caracteriza por uma divisão de áreas funcionais, dentre elas, a gerência de compras. Diferentemente da empresa Alfa, a empresa Beta não está submetida a uma relação monopolística frente aos fornecedores, e busca estabelecer relações de parceira com eles.

Como política de relacionamento, Beta trabalha com a manutenção de exclusividade junto ao fornecedor para cada matéria-prima - exceção feita àquelas fortemente padronizadas, como pranchas de madeira. Os resultados desta política são a garantia de fornecimento e de preço estável, mesmo em períodos de oscilação no mercado, e o compartilhamento da gestão de itens comprados, como é o caso das embalagens, entregues pelo fornecedor no dia anterior à produção de um determinado lote. 
Esta aproximação dos fornecedores está permitindo à empresa Beta uma reconfiguração na emissão de pedidos, migrando de um sistema em que dois pedidos são emitidos a cada mês, para um novo sistema puxado pela demanda, em que os pedidos de compra serão emitidos, logo após a entrada dos pedidos dos clientes, reduzindo, portanto, o nível de estoque de segurança - que hoje oscila entre 10 e 15 dias -, como também trazendo a reboque as vantagens de um sistema Just in Time.

Além dos benefícios tangíveis agregados pela política de relacionamento junto aos fornecedores, vale destacar o fato de os parceiros estarem localizados em São Paulo e no Sul do país, fora da região de produção da empresa. Este fato contradiz o argumento utilizado pela empresa Alfa ao justificar a opção de se trabalhar com um número reduzido de fornecedores, dado que estes estariam distantes e suscetíveis a não atender à demanda da empresa.

Embora seja possível apontar vários aspectos favoráveis à política de relacionamento adotada pela empresa Beta, verificou-se a existência de elementos subjacentes a esta política, que abrem outra perspectiva de análise, na qual a tentativa de estabelecer um relacionamento duradouro é atribuída aos fornecedores da empresa Beta.

“(...) da mesma forma que nós temos nossos clientes fiéis nós temos nossos fornecedores fiéis. (...) Graças a Deus, todos os fornecedores que estão com a gente brigam para ficar e os que estão lá fora brigam para entrar, porque eles querem ter a empresa Beta na fábrica deles (dos fornecedores) também. Graças a Deus eu ouvi de uma pessoa outro dia, que é representante, que o nosso volume de produtos (compra de matéria-prima) para ele não interessava. O que interessava era vender para empresa Beta. Interessava era mostrar para os outros clientes dele que tem a empresa Beta como cliente, para mostrar que o produto dele é bom, que pode ser comercializado. Então, isso é uma coisa que fortalece nossa marca também" (E1).

Os vários elementos explícitos indicam a percepção do entrevistado a respeito do amplo poder exercido na transação pela empresa Beta. A fidelização, comumente atribuída ao cliente, desloca-se para o fornecedor. Assim, o fornecimento de matérias-primas para a empresa Beta é permeado por disputas entre os fornecedores, nas quais existe uma forte carga simbólica em que o status de fornecedor da empresa Beta legitima a qualidade da matéria-prima.

O que parece crítico neste cenário é a possibilidade de um olhar unifocal, lançado apenas para o interior da empresa, fortalecendo sobremaneira a percepção de poder nas transações e reduzindo as possibilidades de alinhamento com a necessidade dos fornecedores, fundamental em orientação para parcerias. Para corroborar esta ilação, resgata-se aqui o pensamento da direção da empresa, no que diz respeito à concorrência existente no nicho de atuação da empresa Beta. 
"Hoje, são os concorrentes que se espelham na gente. Estão buscando o que a empresa Beta fez para crescer. Então, a gente investe muito na empresa, muito no ser humano aqui dentro, um investimento muito alto no ser humano, por isso eu acho que a gente nem pensa no concorrente, vamos falar a verdade! A gente pensa na gente, o concorrente é quem tem que pensar na gente. A gente tem esse lema aqui dentro da empresa. Não tem que estar preocupado com o que o fulano de tal está fazendo, a gente preocupa com o que nós estamos fazendo, se está tendo o final, tendo a satisfação do cliente" (E1).

Quanto aos aspectos funcionais do setor de compras, verificou-se que a empresa utiliza o consumo médio de materiais para a previsão de compras. A partir do volume previsto, são emitidos dois pedidos mensais - compra a prazos de entrega de 5 dias para os fornecedores de São Paulo e 10 dias para os do Sul do país - de forma que a fragmentação dessas entregas possa suavizar os efeitos de se trabalhar com estoque de segurança, atualmente entre 15 e 20 dias. As atividades de entrada do setor do setor de estoque são programadas a partir da previsão fornecida pelo setor de compras. Embora as atividades de estoque sejam posteriores às compras, são comuns colocações de pedido por parte do setor de compras, após o repasse de informação do setor de estoques, particularmente quando o nível do estoque de segurança reduz consideravelmente.

Quanto às saídas de materiais, estas são planejadas com base na programação de produção gerada pelo PCP. O setor recebe uma listagem com os lotes a serem produzidos e repassa ao setor de produção os materiais necessários. Em casos em que há atraso na produção, o setor de estoques assume a responsabilidade de "segurar" os materiais, dado a reincidência de extravios devido ao não uso imediato pelo setor de produção.

Para o entrevistado E4, a grande dificuldade do setor de estoque decorre de intermediar a relação entre compras e produção, algo já presente na empresa Alfa. O principal problema, segundo relatos da gerência de estoques, diz respeito ao não atendimento das necessidades relativas ao setor de compras que se deve, em parte, à sobrecarga sofrida por este setor.

\footnotetext{
"Eles (o setor de compras) estão sobrecarregados com muita coisa em cima, e, às vezes, a gente passa para lá as nossas necessidades e elas não são atendidas. Eu diria que hoje esse é o maior problema que a gente tem" (E4).
}

Neste caso, os problemas são detectados no processo de compra e entrega do material requisitado, principalmente por não haver um fluxo de informações que interligue o atendimento do fornecedor com o setor de estoques via compras, ou por este se mostrar deficiente. 
Figura 2 - Síntese da formação de estratégias logísticas na empresa Beta

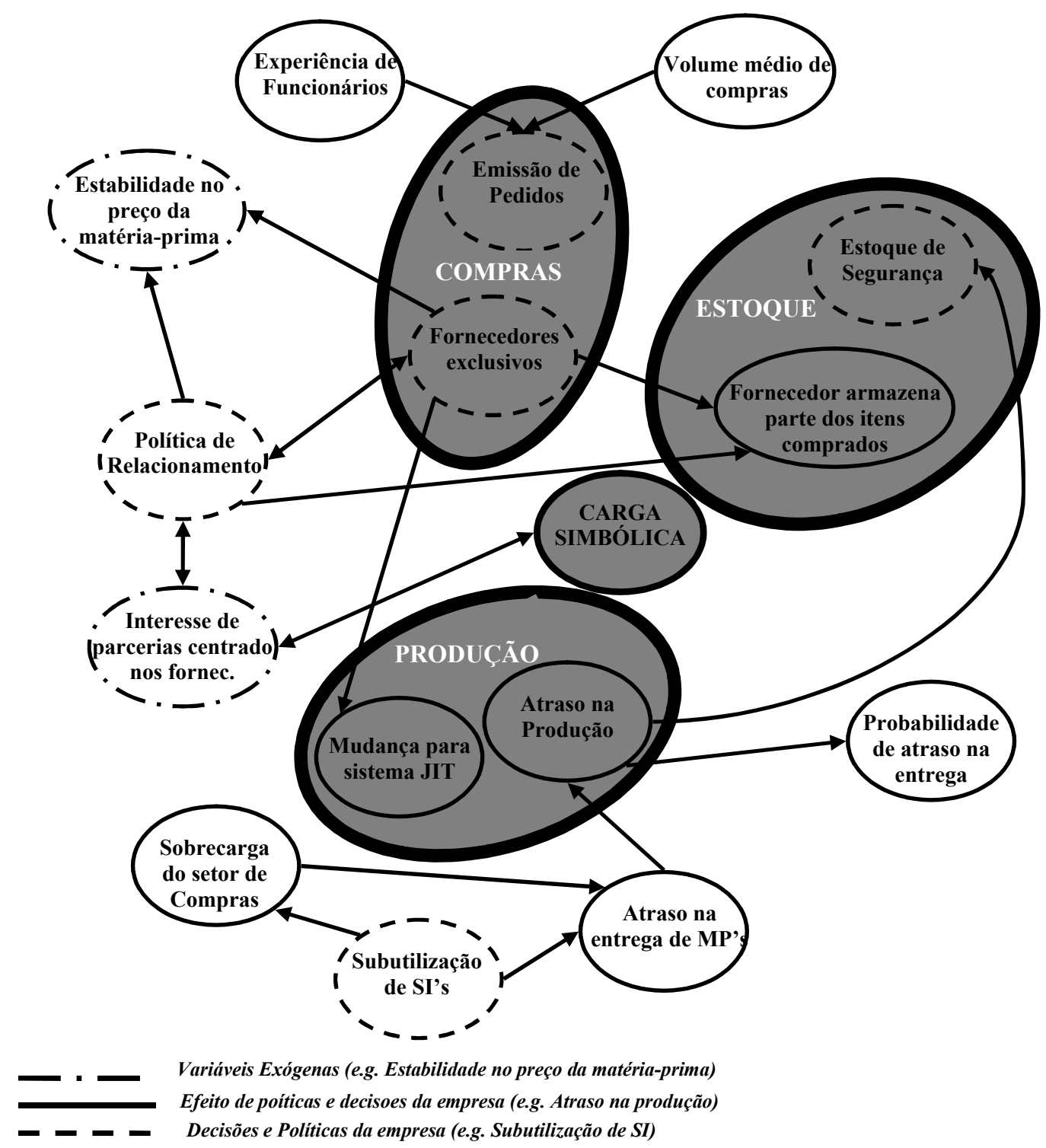

Fonte: Dados da pesquisa

No entendimento dos respondentes, a adoção deste tipo de política tem possibilitado à empresa algumas vantagens como garantias de preço, armazenamento de parte dos itens comprados e a divisão dos pedidos, também como a migração para um sistema Just in Time para uma parcela das matérias-primas. Porém, vale destacar que as falas dos entrevistados centram o interesse desse tipo de parceria nos fornecedores, que legitimariam a qualidade de seus produtos ao fornecerem-nos à empresa Beta.

Outro aspecto que diferencia as políticas de compra das empresas Alfa e Beta é fato desta ter como base o volume médio de consumo de matérias, e aquela, a entrada de pedidos no sistema. Em comum, a presença da experiência de funcionários, para identificar a necessidade de compra para determinados materiais, complementando o auxílio do SI. 
Todavia, aspectos de informação acerca da necessidade de materiais têm causado alguns problemas à empresa, culminando em atritos entre os setores de compra, estoque e produção. Em alguns casos, há uma falha na colocação de pedidos junto aos fornecedores, em outros, um atraso na entregue desses materiais, com o agravante de não haver uma cobrança por parte do setor de compras. Em decorrência destas disfunções, verifica-se a falta de alguns materiais para a produção que comprometem o planejamento da empresa até a entrega ao cliente final.

A recorrência desse tipo de problema chama a atenção para o que há de subjacente no que a empresa determina como relação de parceria junto aos fornecedores. As transações têm apresentado pontos incongruentes, uma vez que a empresa obtém o que, a princípio, seriam benefícios, mas em função destes mesmos benefícios, decorrem-se atrasos na entregue que comprometem as demais atividades. Como alternativa a esta incongruência, vale destacar que, assumidamente, o estoque de segurança tem como função cobrir os atrasos na entrega de matéria-prima, tornando explícito que este atraso é uma premissa, mesmo no que a empresa atribui ser uma relação de parceria.

\section{Análises e conclusões dos casos sob a ótica da network theory}

A criação de um novo conjunto de atividades a partir de adaptações nos processos desempenhados pelos clientes e fornecedores, em função de relacionamentos mais colaborativos, representa, segundo a abordagem da Network Theory, uma forma de coordenação capaz de incrementar o desempenho das empresas e aprimorar a utilização dos recursos disponíveis.

Em cadeias de suprimento que atuam em setores econômicos competitivos, as empresas têm buscado novos padrões de fornecimento, adquirindo insumos de maneira tempestiva. Novos padrões de flexibilidade produtiva, disponibilidade de estoque e freqüência e pontualidade de entrega passaram a ser exigidos dos fornecedores. Dessa maneira, um novo conjunto de habilidades e uma nova estrutura de recursos emergiram, para que as empresas pudessem adaptar com sucesso as atividades desempenhadas a esse novo tipo de responsabilidade. Como resultado, um novo padrão de relacionamento aprofundado vem sendo estabelecido pelos clientes, a fim de combinar o conjunto de competências possuídas pelos fornecedores com os daquelas empresas.

Além disso, as empresas têm buscado o desenvolvimento de novas competências conjuntas, o que requer compartilhamento de capacidades e adaptações na estrutura de atividades, possíveis somente em ambientes de forte vínculo colaborativo entre os atores. A integração dos fornecedores em projetos de desenvolvimento de novos produtos é um exemplo do grau de interação estabelecido nas cadeias de suprimento colaborativas.

Quanto ao padrão de relacionamento estabelecido pela empresa Alfa e seus fornecedores, o que se verifica é que a preocupação prioritária dessa empresa está na utilização da sua identidade 
como aspecto de poder perante os fornecedores, seja para adqurir componentes a baixo custo, seja para se proteger de ações oportunísticas de seus fornecedores estratégicos.

Além disso, não há interferência praticamente nenhuma dos fornecedores na formação da identidade da empresa Alfa, exceto pela capacidade daqueles em fornecer itens a baixo custo à empresa estudada. Esse fenômeno demonstra haver um baixo grau de interação entre ela e seus fornecedores. Empresas que se envolvem em relacionamentos colaborativos, segundo a Network Theory, tornam-se mais comprometidas entre si, em um processo de construção de uma identidade que reflita o tipo de vínculo estabelecido entre elas (SKJOETT-LARSEN, 1999).

Não parece ser este o caso da empresa Beta, que afirma ter a sua identidade na cadeia de suprimentos vinculada à sua capacidade de estabelecer relacionamentos colaborativos com fornecedores. Isto, por si só, seria um fator de captação e manutenção de bons fornecedores, algo que esta empresa parece valorizar mais do que a empresa Alfa.

Adaptações entre atividades não foram verificadas no caso de Alfa, exceto quando ela tomou a iniciativa de importar aço como alternativa de suprimento, o que desencadeou a expectativa de retaliação por parte de seus dois fornecedores nacionais do insumo. Dessa maneira, não há indícios de que ela desenvolva, em conjunto com seus fornecedores, uma nova estrutura de atividades relacionadas aos processos produtivos e de abastecimento. Projetos colaborativos não foram implantados para o desenvolvimento de uma estrutura dinâmica de novos recursos entre a díade Alfa-fornecedor. Nesses casos, o fornecimento de recursos complementares ocorre em um ambiente pouco colaborativo, em que o vínculo entre as partes reforça-se somente pela identidade da empresa Alfa - ou seja, o uso de seu poder como cliente importante -, sem que questões como aprendizado conjunto sejam motivadores para o padrão de relacionamento estabelecido.

Novamente, tais adaptações parecem ocorrer de maneira diferente no caso da empresa Beta. Ao afirmar que a política de relacionamentos com fornecedores permitiu a obtenção de vantagens ligadas ao armazenamento de parte dos itens adquiridos, a divisão de pedidos e a migração para um sistema mais próximo do Just in Time para uma parcela das matérias-primas, a empresa sinaliza uma forte adaptação mútua - nela e em seus fornecedores - na estrutura de atividades desempenhadas, o que denota uma ação colaborativa entre os atores.

Dessa maneira, a função do relacionamento mantido entre Alfa e seus fornecedores exerce menos impacto do que se poderia esperar nas três esferas de análise da Network Theory - estrutura de atividades, de recursos e de atores. Em compensação, no caso de Beta, surge uma perspectiva de incremento do desempenho da empresa em função única e exclusivamente do padrão de relacionamento mantido por ela em sua cadeia de suprimentos.

As funções de um relacionamento se evidenciam à medida que novos recursos são criados, novas combinações de atividades emergem e conhecimento é obtido pelas empresas envolvidas, 
gerando oportunidades para o desenvolvimento de capacidades, recursos e atividades (HAKANSSON; SNEHOTA, 1995).

As empresas devem combinar suas estruturas internas de recursos com a estrutura de recursos possuída pelos fornecedores como única maneira de tornarem-se mais eficientes e responsivas às demandas dos clientes. A função compras exerce um papel destacado nesse aspecto, pois é por meio de projetos colaborativos com fornecedores, da coordenação na execução das atividades internas e externas, e do estabelecimento de relacionamentos colaborativos com os demais atores estratégicos que uma empresa se habilita a estabelecer uma vantagem competitiva sustentável em sua indústria, segundo a abordagem da Network Theory (GADDE; HAKANSSON, 2001).

Portanto, verifica-se que a política de suprimentos da empresa Alfa leva à execução da função compras de forma operacional, em uma perspectiva de curto prazo, uma vez que ela tem um foco prioritariamente voltado para a garantia do fluxo de recursos de forma ininterrupta, a baixo custo. Há evidências, a partir desta pesquisa, que a função compras na empresa pouco interfere, por exemplo, no desenvolvimento das capacidades e competências dos fornecedores.

A função compras tem demonstrado, ao longo das últimas décadas, forte potencial de contribuição para a obtenção de vantagens competitivas em diversas organizações e cadeias de suprimento. Para isso, deve ser desempenhada conforme o modelo de atuação estratégica, cujo foco está na busca de soluções que garantam o fluxo de recursos para a empresa, ao mesmo tempo em que atua na coordenação entre as atividades desempenhadas internamente e aquelas executadas pelos fornecedores e estabelece o vínculo adequado com os atores integrantes do círculo de relacionamentos da empresa.

Este é o caso da empresa Beta, quando parece prevalecer uma perspectiva estratégica, de longo prazo, na atuação da função compras. Seu foco parece ser a obtenção de benefícios advindos de uma política de suprimento voltada para relacionamentos colaborativos com fornecedores.

Dessa maneira, pode-se concluir que, segundo a ótica da Network Theory, a política de suprimentos adotada pela empresa Alfa interfere negativamente em seu desempenho, especialmente pelo fato de se verificar o estabelecimento de vínculos frágeis entre ela e seus fornecedores. No caso da empresa Beta, a política de suprimentos, quando analisada sob a ótica teórica apresentada neste artigo, oferece uma perspectiva positiva de impacto no desempenho da empresa, tendendo a fortalecer os vínculos estabelecidos com atores importantes da cadeia de suprimentos. 


\begin{abstract}
This study analyzed the supply strategies of two medium-sized companies in the furniture sector, especially as regards the management of supplier relationships. The research is characterized by being a multi-case study of a qualitative, descriptive approach, and used content analysis (CA) as method to analyze the semi-structured interviews. The theoretical model of the analysis was supported by the Network Theory, especially from its basic tenets (actors, activities and resources) for the analysis of the strategies used by the purchasing function in companies to: coordinate the activities performed by suppliers; combine internal with external resources; manage collaboration initiatives between the company and suppliers. The study found that the different supply strategies used by the two companies have different impacts on their performances. The first company is affected negatively, particularly by the noncollaborative policy of dealing with suppliers. The second company is affected in a positive way, achieving significant gains from collaboration with their suppliers.
\end{abstract}

Key-words: supply chain; networking theory; logistic performance; furniture sector.

\title{
Referências
}

BARDIN, L. Análise de Conteúdo. Lisboa: Edições 70, 1977.

BRITO, C. M.; ROSEIRA, C. A model for the understanding of supply chain networks. IMP Group. 2003. Disponível em $<$ http://www.impgroup.org > Acesso em: 06 Agosto 2007.

FORD, D.; GADDE, L. E.; HÅKANSSON, H.; SNEHOTA, I. Managing business relationships. $2^{\mathrm{a}}$ ed. Chiscester, Inglaterra: John Wiley \& Sons, 2003.

GADDE, L. E.; HÅKANSSON, H. Supply network strategies. Chichester: John Wiley \& Sons, 2001.

HÅKANSSON, H.; SNEHOTA, I. Developing relationships in business networks. Londres: Routledge, 1995.

MONCZKA, R.; TRENT, R.; HANDFIELD, R. Purchasing and supply chain management. 2th Ed. Cincinnati: Thomson Learning, 2002.

OLSEN, N. V. Incremental product development: four essays on activities, resources and actors. 2006. Tese (Doutorado). BI Norweggian School of Management. Disponível em <http:/www.impgroup.org> Acesso em: 06 Agosto 2007.

SEIDMAN, I. E. Interviewing as Qualitative Research: a guide for researchers in neducation and social sciences. New York: Columbian University, 1991.

SKJOETT-LARSEN, T. Supply chain management: a new chalenge for researchers and managers in logistics. International Journal of Logistics Management. v. 10. Issue 2. p. 41. 1999.

cross ${ }^{\text {ref }}$

TRIVIÑOS, A. N. S. Introdução à Pesquisa em Ciências Sociais: a pesquisa qualitativa em educação. São Paulo: Atlas, 1987.

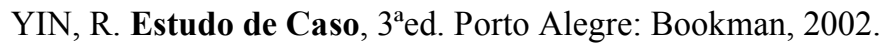

\section{Dados dos autores:}

\section{Nome completo: Wescley Silva Xavier}

Filiação institucional: Universidade Federal de Minas Gerais

Departamento: Centro de Pós-Graduação e Pesquisas em Administração (CEPEAD/UFMG)

Função ou cargo ocupado: Doutorando em Administração

Endereço completo para correspondência: Av. Pres. Antônio Carlos, 6.627 CEP 31270-901 - Belo 
Horizonte - MG

Telefones para contato: (31) 8679-8055

e-mail: wescleysxavier@yahoo.com.br

Nome completo: Osmar Vieira de Souza Filho

Filiação institucional: Universidade Federal de Minas Gerais

Departamento: Centro de Pós-Graduação e Pesquisas em Administração (CEPEAD/UFMG)

Função ou cargo ocupado: Mestre em Administração e Pesquisador do Núcleo Interdisciplinar de Pesquisa e Extensão em Logística (NIPELOG/UFMG)

Endereço completo para correspondência: Av. Pres. Antônio Carlos, 6.627 CEP 31270-901 - Belo

Horizonte $-\mathrm{MG}$

Telefones para contato: (31) 9981-0914

e-mail: osmar.br@gmail.com

Nome completo: Ricardo Silveira Martins

Filiação institucional: Universidade Federal de Minas Gerais

Departamento: Centro de Pós-Graduação e Pesquisas em Administração (CEPEAD/UFMG)

Função ou cargo ocupado: Professor do Centro de Pós-Graduação e Pesquisa em Administração (CEPEAD)/Universidade Federal de Minas Gerais (UFMG). Pesquisador do Núcleo Interdisciplinar de Pesquisa e Extensão em Logística (NIPE-LOG/UFMG)

Endereço completo para correspondência: Av. Pres. Antônio Carlos, 6.627 CEP 31270-901 - Belo Horizonte - MG

Telefones para contato: (31) 8717-9564

e-mail: ricardomartins.ufmg@gmail.com 